\title{
Keefektifan Teknik Behavior Contract Dalam Bingkai Konseling Kelompok Behavioral Untuk Mereduksi Prokrastinasi Akademik Siswa
}

\author{
Dwi Kresminia Ningsih', IM. Hambali2, Diniy Hidayatur Rahman ${ }^{3}$ \\ dwikresmi@gmail.com¹, im.hambali.fip@um.ac.id², diniy.hidayatur.fip@um.ac.id ${ }^{3}$ \\ Program Studi Bimbingan dan Konseling, Fakultas IImu Pendidikan ${ }^{123}$ \\ Universitas Negeri Malang123
}

\begin{abstract}
Academic procrastination was are commonly found in many schools. It is proved by the result of survey in SMPN 1 Kesamben, Blitar which showed 53\% of students did academic procrastination. One of the effective counseling techniques to reduce academic procrastination is behavior contract through behavioral group counseling. This study aimed to test the effectiveness of Behavior Contract technique through behavioral group counseling to reduce students' academic procrastination. This Study used One Group Pretest-Posttest design. The subjects of the study were 6 students found by purposive sampling. The research data was collected by academic procrastinations scale. The data analysis result using Wilcoxon Signed Rank Test showed the score of asymp.sig.(2-tailed) equal to 0.028 . Those result indicated that behavior contract technique through behavioral group counseling was effective to reduce students' academic procrastination.
\end{abstract}

Keywords: behavioral counseling, behavior contract, academic procrastination

\begin{abstract}
Abstrak
Fenomena prokrastinasi akademik banyak dijumpai di lingkungan sekolah. Hal ini dibuktikan dengan hasil survei di SMPN 01 Kesamben, Blitar yang menunjukkan bahwa 53\% siswa melakukan prokrastinasi akademik. Salah satu teknik konseling yang efektif untuk mereduksi prokrastinasi akademik adalah behavior contract dalam bingkai konseling kelompok behavioral. Penelitian ini bertujuan untuk mengetahui kefektifan teknik behavior contract dalam bingkai konseling kelompok behavioral untuk mereduksi prokrastinasi akademik siswa. Penelitian ini menggunakan desain one group pretest-posttest. Subjek penelitian berjumlah 6 siswa yang diperoleh dengan purposive sampling. Data penelitian dikumpulkan dengan menggunakan Skala Prokrastinasi Akademik. Analisis data dengan Wilcoxon Signed Rank Test menghasilkan nilai asymp.sig.(2-tailed) sebesar 0.028. Nilai tersebut berarti bahwa teknik behavior contract dalam bingkai konseling kelompok behavioral efektif untuk mereduksi prokrastinasi akademik siswa.
\end{abstract}

Kata Kunci: konseling behavioral, behavior contract, prokrastinasi akademik

\section{PENDAHULUAN}

Dalam pelaksanaan aktivitas belajar, siswa berkewajiban untuk mengerjakan dan menyelesaikan tugas akademik yang diberikan disekolah. Adanya pemberikan tugas tersebut, diharapkan siswa dapat menyelesaikan tugas dengan tepat waktu, penuh tanggung jawab agar memperoleh nilai yang memuaskan dan dapat meningkatkan prestasi akademik di sekolah. Namun, fakta dilapangan membuktikan, tidak semua siswa dapat melaksanakan tanggung jawab mengerjakan dan menyelesaikan tugas dengan baik dan maksimal. Kebiasaan menunda-nunda mengerjakan tugas disebut dengan prokrastinasi akademik. Menurut Knaus W (2010), prokrastinasi adalah perilaku menunda aktivitas yang seharusnya terselesaikan tepat waktu. Ferrari, Johnson, \& McCown (1995) mengatakan prokrastinasi adalah menunda aktivitas penting dapat membentuk perilaku di bawah alam sadar, serta mengakibatkan perasaan emosional. Oleh karena itu, dapat dijabarkan bahwa prokrastinasi akademik adalah intensitas menangguhkan kewajiban untuk menuntaskan tugas akademik secara 
sadar, berulang, dapat mengakibatkan gelisah atau cemas sehingga terlambat mengumpulkan tugas dan mengumpulkan, namun hasil tidak maksimal karena tergesa-gesa saat mengerjakan.

Penelitian Nitami, Daharnis \& Yusri (2015) menghasilkan 208 subjek 9\% di antaranya memiliki prokrastinasi akademik berkategori tinggi, $43 \%$ berkategori sedang, $48 \%$ berkategori rendah. Munawaroh,dkk (2017) menemukan 17,2\% siswa SMP memiliki kategori PA tinggi. Widyastari, Atrizka, Ramadhani, \& Damanik (2020) menunjukkan bahwa 127 siswa SMA Swasta Ar-Rahman Medan melakukan perilaku prokrastinasi akademik yang disebabkan rendahnya kontrol diri siswa. Hasil survei di SMPN 01 Kesamben Blitar, menemukan 53\% siswa melakukan prokrastinasi akademik. Data awal perilaku prokrastinasi akademik diperoleh dengan menyebarkan Google Form di kelas VIII C. Hasil analisis data awal tersebut menunjukkan $48,3 \%$ siswa melakukan penundaan menyelesaikan tugas, $27,6 \%$ siswa tidak bisa membagi waktu antara mengerjakan tugas dengan aktivitas lain, 17,2\% siswa penundaan mengerjakan tugas, dan $6,9 \%$ siswa memiliki rasa malas mengerjakan tugas. Berdasarkan data-data tersebut membuktikan bahwa fenomena prokrastinasi akademik banyak ditemui di lingkungan sekolah.

Penyebab prokrastinasi akademik muncul karena keadaan fisik, psikologis serta lingkungan. Hal ini sependapat dengan Ferrari,dkk (1995) menyebutkan penyebab PA karena faktor dalam yaitu keadaan fisik, psikologis serta faktor luar yaitu berasal dari kondisi lingkungan sekitar siswa. Rahman (2019) menyebutkan prokrastinasi akademik dapat juga menyebabkan munculnya pemikiran yang irasional, sikap merendahkan diri dan penuntutan terhadap diri sendiri secara berlebihan. Hambali, Putridari \& Handarini (2017) menyebutkan prokrastinasi akademik dapat menyebabkan munculnya selfesteem dan self-efficacy yang rendah karena siswa tidak percaya dengan kemampuan yang dimiliki sehingga menganggap bahwa tugas akademik menjadi sebuah ancaman.

Prokrastinasi akademik dapat berpengaruh negatif pada perkembangan siswa di sekolah. Pengaruh negatif tersebut antara lain mempengaruhi nilai akademik, menimbulkan perasaan cemas dan menyesal, dan menciptakan kebiasaan belajar yang buruk bagi siswa. Hal ini sependapat dengan Burka \& Yuen (2008) mengatakan dampak internal prokrastinasi akademik adalah muncul perasaan cemas dan bersalah, serta dampak ekternal prokrastinasi akademik adalah mempengaruhi nilai akademik dan prestasi di sekolah.

Prokrastinasi akademik dapat direduksi dengan pemberian teknik konseling yang tepat menggunakan teknik konseling yang efektif yaitu behavior contract dalam bingkai konseling kelompok behavioral. Fauzan (2009) mengatakan teknik behavior contract adalah pembuatan kontrak dengan lebih dari satu orang untuk merancang perilaku tertentu agar mendapat hadiah atas pelaksanaan perilaku tersebut. Latipun (2017) menyebutkan kesepakatan perilaku merupakan keputusan lebih dari dua orang dalam merumuskan tingkah laku baru. Kedua pendapat tersebut dapat disimpulkan behavior contract merupakan kesepakatan lebih dari dua orang dalam merumuskan perilaku baru yang berisikan keinginan dan adanya tanggung jawab yang dipenuhi beserta konsekuensi pelanggaran kontrak tersebut. Teknik behavior contract dapat berfungsi melatih siswa bertanggung jawab dan melatih komitmen dengan diri sendiri untuk mencapai perubahan tingkah laku (Corey,2009). Perubahan tingkah laku yang dimaksud adalah siswa dapat mengumpulkan tugas tepat waktu, tidak menunda tugas, dapat mengatur waktu antara mengerjakan tugas dengan aktivitas lain, serta mengatasi rasa malas mengerjakan tugas akademik. Konseling behavioral melalui teknik behavior contract dilaksanakan dalam suasana kelompok. Komalasari, Wahyuni, \& Karsih (2011) menyebutkan sistem kelompok dapat membuat siswa mendapatkan sumber penambah reinforcement positif, serta mendapat sistem pendukung (support) bagi siswa yang melakukan perubahan nyata untuk membentuk perilaku baru. Sistem kelompok dapat melatih siswa percaya diri untuk berpendapat, melatih kepekaan terhadap masalah pribadi orang lain serta memberikan motivasi untuk melakukan perubahan dan perbaikan perilaku (Romlah,2018).

Teknik behavior contract telah diteliti keefektifannya oleh sekolompok orang. Widiyastuti, Muhammad,\& Sugiyadi (2016) menunjukkan bahwa 11 siswa SMP Negeri 10 Magelang yang memiliki 
ketegori tinggi perilaku prokrastinasi akademik efektif diintervensi dengan konseling kelompok behavioral melalui teknik behavior contract dengan bukti adanya peningkatan skor sebesar $15,3 \%$. Purnama, Marsidi, \& Trisnawati (2019) menunjukkan bahwa 10 siswa kelas XII IPS MAN 2 Banyuwangi yang memiliki ketegori tinggi perilaku prokrastinasi akademik efektif diintervensi dengan teknik behavior contract dalam konseling kelompok behavioral dengan penurunan skor sebesar $27 \%$. Rokhman, Sucipto, \& Masturi (2020) menunjukkan bahwa 3 siswa SMA 1 Gedog Kudus yang memiliki ketegori tinggi perilaku prokrastinasi akademik efektif diberikan intervensi konseling behavioral dengan teknik behavior contract. Shidiq, Mulawarman, \& Awalya (2020) menunjukkan bahwa 16 siswa SMP IT Insan Cendekia Semarang yang memiliki ketegori tinggi perilaku prokrastinasi akademik efektif diintervensi dengan konseling behavioral melalui teknik behavior contract dengan bukti adanya penurunan skor sebesar $29 \%$.

\section{METODE PENELITIAN}

Proses penelitian memakai One Group Pretest-Posttest. Berjalannya proses penelitian dilaksanakan bulan Januari-Februari 2021 di Ruang BK SMP Negeri 01 Kesamben, Blitar secara tertutup dengan mematuhi protokol kesehatan. Prosedur penelitian terdiri dari aktivitas utama dan aktivitas inti. Aktivitas utama yang pertama yaitu deskripsi data yang didalamnya memiliki tiga aktivitas inti yaitu a) tahap persiapan (merancang skala prokrastinasi akademik, analisis hasil validasi dan reliabilitas, pelaksanaan pra treatment dengan menyebarkan Skala Prokrastinasi Akademik untuk pretest); b) tahap pelaksanaan treatment lima pertemuan; c) tahap analisis data posttest dan pelaksanaan pasca treatment. Subjek penelitian berjumlah 6 siswa yang diperoleh dengan purposive sampling. Subjek dipilih berdasarkan skor Skala Prokrastinasi Akademik. Bentuk pemberian skor Skala Prokrastinasi Akademik sebagaimana ditunjukkan pada tabel 2. Data penelitian dikumpulkan dengan menggunakan Skala Prokrastinasi Akademik. Kategori prokrastinasi akademik sebagaimana ditunjukkan pada tabel 3. Data penelitian dianalisis dengan menggunakan Wilcoxon Signed Rank Test.

Tabel 1. One Group Pretest-Posttest (Sugiono,2010)

\begin{tabular}{llll}
\hline Kelompok & Pretest & Treatment & Posttest \\
\hline Eksperimen $(\mathrm{E})$ & $\mathrm{O}_{1}$ & $\mathrm{x}$ & $\mathrm{O}_{2}$ \\
\hline
\end{tabular}

Tabel 2. Bentuk Pemberian Skor

\begin{tabular}{ccccc}
\hline Pernyataan & SS & S & TS & STS \\
\hline Favourable & 1 & 2 & 3 & 4 \\
\hline Unfavourable & 4 & 3 & 2 & 1 \\
\hline
\end{tabular}

Tabel 3. Kategori Prokrastinasi Akademik

\begin{tabular}{lll}
\hline No & Interval & Kategori \\
\hline 1 & $139-184$ & Jinggi \\
\hline 2 & $93-138$ & Sedang \\
\hline 3 & $4-92$ & Rendah \\
\hline
\end{tabular}


Efektor, Volume 8 Issue 2, 2021, Pages 176 - 183

Dwi Kresminia Ningsih'1, IM. Hambali2, Diniy Hidayatur Rahman ${ }^{3}$

\section{HASIL DAN PEMBAHASAN}

Pada tanggal 23 Januari 2021 pelaksanaan pra treatment yang meliputi pemberian pretest pada kelas VIII C berjumlah 32 siswa melalui google meet dan google form. Dari hasil pretest diperoleh 6 siswa yang memiliki prokrastinasi akademik berkategori tinggi, 26 siswa berkategori sedang, dan tidak ada siswa berkategori rendah. Hasil pretest prokrastinasi akademik sebagaimana ditunjukkan pada gambar 1.

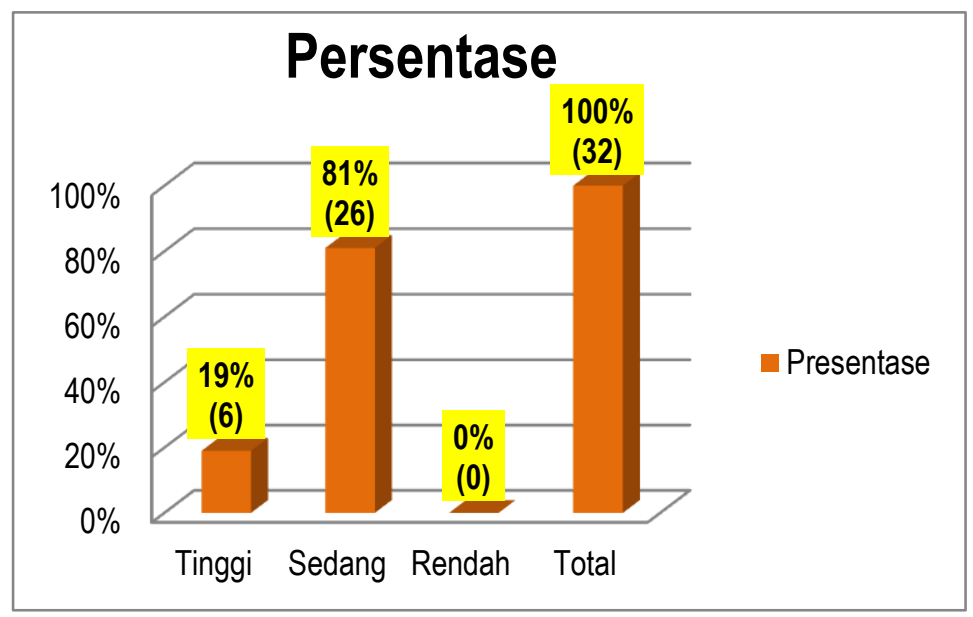

\section{Gambar 1 Hasil Pretest Prokrastinasi Akademik}

. Hasil pretest prokrastinasi akademik menemukan 6 siswa berkategori tinggi. Artinya siswa tersebut secara terus-menerus tidak mengumpulkan tugas tepat waktu, mengerjakan tugas tidak maksimal karena adanya deadline tugas, memiliki rasa malas mengerjakan tugas, melakukan aktivitas yang lebih asik, tidak bisa mengelola waktu, sehingga akan berdampak pada nilai sekolah, kenaikan kelas, dan sering mendapatkan stereotip dari siswa lain dan guru. Hal ini sependapat dengan Ferrari, Johnson, \& McCown (1995) tipe prokrastinasi akademik tinggi adalah tidak pernah mengumpulkan tugas sekalipun tugas itu memiliki waktu deadline pengumpulan tambahan sehingga sering berdampak pada prestasi di sekolah, memiliki perilaku malas mengerjakan tugas dan sering mendapat judgement dari lingkungan sekitar. Siswa yang memiliki kategori prokrastinasi akademik tinggi tersebut diberikan treatment teknik behavior contract dalam bingkai konseling kelompok behavioral.Treatment dilaksanakan pada saat jadwal kosong siswa, kesediaan siswa atas persetujuan orang tua untuk datang ke sekolah. Treatment dilaksanakan Hari Kamis dan Sabtu dimulai pada tanggal 30 Januari 2021 sampai 13 Februari 2021. Kegiatan treatment dilaksanakan dalam 5 kali pertemuan. Setiap pertemuan memiliki topik berbeda, tujuan berbeda, yang berdurasi 60 menit sampai 90 menit, serta disetiap pertemuan diberikan tugas atau homework.

Pada 13 Februari 2021, pemberian posttest kepada 6 siswa yang bertujuan untuk mengetahui keadaan prokrastinasi akademik setelah diberikan 5 kali treatment teknik behavior contract dalam bingkai konseling kelompok behavioral. Hasil analisis pretest dan posttest menunjukkan terjadi penurunan skor kategori prokrastinasi akademik yang semula berkategori tinggi menjadi kategori rendah. Perbandingan pretest dan posttest prokrastinasi akademik sebagaimana ditunjukkan pada gambar 2. 
Efektor, Volume 8 Issue 2, 2021, Pages 176 - 183

Dwi Kresminia Ningsih'1, IM. Hambali2, Diniy Hidayatur Rahman ${ }^{3}$

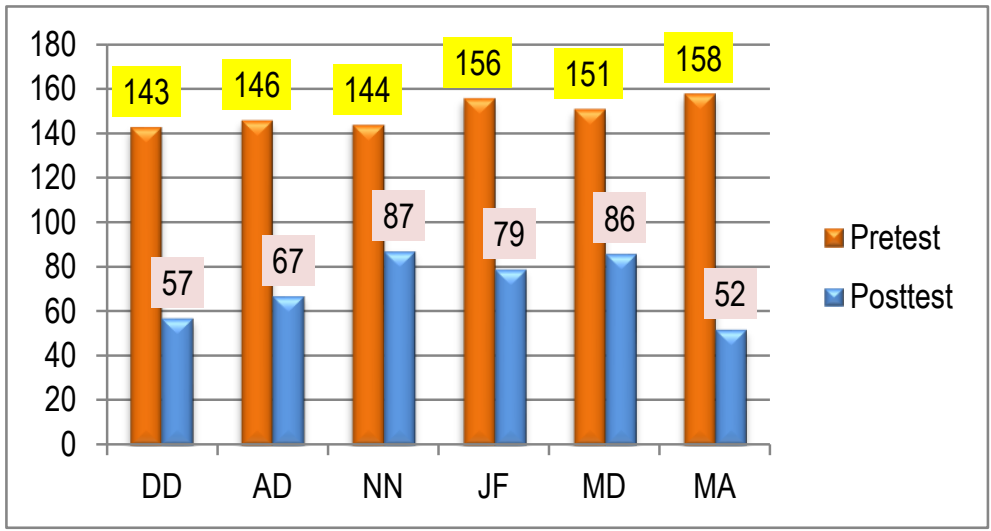

Gambar 2 : Perbandingan Pretest dan Postest Prokrastinasi Akademik

Uji hipotesis dianalisis dengan menggunakan Wilcoxon Signed Rank Test. Skor yang diperoleh responden saat pretest akan dibandingkan dengan skor posttest. Analisis Wilcoxon Signed Rank Test berlaku ketentuan $\mathrm{H}_{0}$ kurang dari 0.05 tidak diakui. Analisis hasil menunjukkan bahwa terdapat penurunan skor prokrastinasi akademik. Hasil uji hipotesis pada tabel 5 dengan Wilcoxon Signed Rank Test menunjukkan nilai $(0,028<0,05)$. Skor tersebut berarti bahwa teknik behavior contract dalam bingkai konseling kelompok behavioral efektif untuk mereduksi prokrastinasi akademik siswa.

Tabel 4 Wilcoxon Signed Rank Test Statistics

\begin{tabular}{|l|r|}
\hline \multicolumn{2}{|c|}{ Test Statistics $^{\mathrm{a}}$} \\
\hline & \multicolumn{1}{|c|}{ Posttest - Pretest $^{-2.2010}$} \\
\hline $\begin{array}{l}\text { Asymp. Sig. (2- } \\
\text { tailed) }\end{array}$ &, 028 \\
\hline \multicolumn{2}{|l|}{ a. Wilcoxon Signed Ranks Test } \\
\hline \multicolumn{2}{|l|}{ b. Based on positive ranks. } \\
\hline
\end{tabular}

Pendekatan behavioral dipilih karena dalam kehidupan sehari-hari siswa saling berinteraksi dengan lingkungan sekitar, sehingga terdapat proses belajar siswa dari lingkungan sekitar. Hal ini sependapat dengan tokoh pencetus teori behaviorisme yaitu B.F Skinner mengatakan, perilaku manusia ditentukan oleh apa yang terjadi disekitarnya, dan manusia bukan dikontrol oleh dirinya, melainkan dikontrol oleh penguat (reinforcement) dan lingkungan (Corey,2009). Ketika siswa berada pada lingkungan pertemanan yang selalu menunda tugas sekolah, tidak pernah mengerjakan tugas, selalu terlambat mengumpulkan tugas, asik bermain game sampai lupa waktu sekolah, sehingga siswa merasa perilaku penundaan tugas sudah benar dan tidak masalah bagi dirinya. Hal tersebut sejalan dengan pendapat Fauzan,(1992) mengatakan perilaku maladaptive berasal dari hasil belajar yang dipelajari melalui interaksinya dengan lingkungan. Artinya siswa belajar dari lingkungan sekitarnya tentang penyikapan adanya tugas akademik disekolah dan siswa merasa tidak apa-apa jika tugas akademik tidak dikerjakan dan tidak dikumpulkan. Oleh sebab itu dibutuhkan kontrolisasi dari lingkungan sekitar dapat membuat siswa menyikapi adanya tugas dengan baik dan dikerjakan dengan maksimal. Selain itu, siswa yang memiliki prokrastinasi akademik sangat membutuhkan motivasi belajar yang baik dari siswa dan lingkungan siswa. 
Teknik behavior contract dapat menurunkan prokrastinasi akademik karena dalam teknik tersebut terdapat sistem reward dan punishment. Kedua sistem tersebut dapat berfungsi untuk melatih siswa membentuk perilaku baru dan bertanggung jawab dalam pelaksanaan perilaku baru. Hal ini sependapat dengan Fauzan (2009) menyebutkan salah satu unsur-unsur merancang kontrak perilaku adalah adanya pemberian sanksi atau punishment dan pemberian bonus atau reward yang berfungsi untuk membentuk perilaku baru dan tanggung jawab. Komalasari, Wahyuni \& Karsih (2011) menyebutkan faktor-faktor keberhasilan teknik behavior contract adalah pemberian penghargaan dan sanksi agar dapat berkomitmen, pemberian homework agar mandiri mengevaluasi diri, kebebasan menulis kontrak perilaku agar dapat berkomitmen dengan diri sendiri, serta membutuhkan pantauan orang lain dalam melihat perkembangan perilaku baru. Teknik behavior contract membuat siswa menjadi pribadi yang bertanggung jawab dan memiliki komitmen untuk mengurangi perilaku prokrastinasi akademik. Komalasari, Wahyuni \& Karsih (2011) mengatakan kontrak perilaku dapat melatih sikap tanggung jawab siswa atas apa yang sudah dituliskan sesuai tujuan yang akan telh ditetapkan.

Prokrastinasi akademik dapat direduksi oleh siswa dengan kontrolisasi lingkungan sekitar. Penelitian Asif (2011) menyatakan prokrastinasi akademik siswa dapat direduksi dengan bimbingan orang sekitar dan pola pikir siswa tentang tugas. Terdapat penurunan kategori prokrastinasi akademik tinggi pada 6 siswa, dikarenakan ada beberapa faktor dari dalam dan luar diri siswa (Komalasari, Wahyuni \& Karsih, 2011). Faktor dari dalam atau internal dapat meliputi pemahaman siswa tentang pentingnya mengerjakan tugas, paham tentang dampak prokrastinasi akademik, pemahaman tentang pentingnya mengerjakan tugas tepat waktu dan meningkatkan prestasi di sekolah. Faktor dari luar atau eksternal meliputi adanya perjanjian kontrak dengan konselor untuk dapat mengurangi prokrastinasi akademik dengan rencana, konsekuensi yang telah ditulis sendiri oleh siswa. Hal tersebut secara langsung dapat mengontrol siswa melakukan perilaku baru. Faktor-faktor tersebut muncul ketika siswa diberikan treatment pertemuan pertama sampai pertemuan kelima. Selain dari pemahaman terhadap pentingnya menyelesaikan tugas tepat waktu, pembiasaan dan penguatan juga menjadi salah satu keberhasilan siswa dalam menurunkan perilaku prokrastinasi akademik. Hasil penelitian Kartadinata \& Sia (2008) penyebab prokrastinasi akademik yang dilakukan siswa adalah rasa malas, rasa kewalahan, tidak bisa mengatur waktu untuk mengerjakan tugas sehingga lebih memilih menunda tugas yang diberikan. Hal tersebut selaras dengan faktor penyebab prokrastinasi akademik yang dilakukan siswa yaitu rasa malas mengerjakan tugas karena lelah belajar daring atau online, berkurangnya motivasi belajar sehingga siswa memilih aktivitas menyenangkan, serta membantu pekerjaan orang tua sehingga siswa belum bisa mengatur waktu dengan baik antara mengerjakan tugas akademik dan aktivitas yang lain. Ferrari, Johnson, \& McCown (1995) menjabarkan faktor penyebab prokrastinasi akademik siswa yaitu kondisi fisik, psikologis serta kondisi lingkungan siswa.

Pada pelaksanaan teknik behavior contract konselor memberikan kebebasan kepada siswa untuk menentukan sendiri perilaku yang akan dicapai dan konsekuensi positif serta negatif yang akan diberikan kepada diri sendiri jika melaksanakan atau melanggar isi perjanjian tersebut. Hal ini bertujuan untuk melatih tanggung jawab dan komitmen siswa dengan diri sendiri untuk mencapai perubahan perilaku baru untuk mereduksi prokrastinasi akademik. Hal ini sepedapat dengan Corey (2009) menyebutkan bahwa manfaat pemberian teknik behavior contract yaitu a) mengarahkan ketercapaian perubahan pada siswa; $b$ ) individu lebih disiplin bertingkah laku dan bertanggung jawab atas komitmen yang dibuat sendiri; c) tingkat kepercayaan diri individu meningkatkan; d) individu percaya dapat mengubah perilaku yang merugikan menjadi perilaku baru yang positif.

Pelaksanaan kontrak perilaku dapat dilaksanakan baik oleh siswa. Walaupun saat pelaksaannya siswa menemui hambatan. Namun siswa telah mampu mengatasi hambatan tersebut. Kontrak perilaku dibuat dengan sederhana mungkin, sehingga siswa mudah dan paham cara menyusun kontrak perilaku. Saat menulis kontrak perilaku, kontrak disusun dengan kalimat positif dan penuh dengan motivasi. Pemberian reward sangat dinginkan oleh siswa sehingga memunculkan sikap optimis 
kepada siswa untuk melakukan kontrak perilaku agar mendapat reward yang diinginkan. Siswa juga akan mendapatkan hukuman yang dipilih sendiri saat tidak melaksanakan kontrak perilaku. Hal ini sependapat dengan Fauzan (2004) menyebutkan beberapa hal yang penting untuk menyusun kontrak perilaku yaitu a) membuat kontrak dengan kalimat positif; b) mengatur tugas dan target yang mungkin tercapai; c) reinforment diberikan secara cepat; d) mendorong timbulkan self-countracting atau dorongan untuk siswa agar mampu berkomitmen dalam membentuk perilaku baru; e) menggunakan serial kontrak.

Hasil penelitian dengan analisis Wilcoxon Signed Rank Test memaparkan teknik behavior contract dalam bingkai konseling kelompok behavioral tepat untuk menurunkan perilaku PA 6 siswa. Hasil penelitian juga memaparkan terjadi penurunan skor tinggi menuju rendah sesudah diperlakukan 5 kali treatment teknik behavior contract dalam bingkai konseling kelompok behavioral. Efektivitas teknik behavior contract dalam penelitian ini telah diperkuat dengan penelitian terdahulu. Widiyastuti, Muhammad, \& Sugiyadi (2016), menunjukkan bahwa 11 siswa SMP Negeri 10 Magelang yang memiliki ketegori tinggi perilaku prokrastinasi akademik efektif diintervensi dengan konseling kelompok behavioral melalui teknik behavior contract dengan bukti adanya peningkatan skor sebesar $15,3 \%$. Rokhman, Sucipto, \& Masturi (2020) menunjukkan bahwa 3 siswa SMA 1 Gedog Kudus yang memiliki ketegori tinggi perilaku prokrastinasi akademik efektif diberikan intervensi konseling behavioral dengan teknik behavior contract. Mahardika (2020), menunjukkan bahwa 8 siswa SMA 1 Jakenan yang memiliki masalah disfungsional prokrastinasi akademik efektif diberikan intervensi dengan konseling kelompok melalui teknik behavior contract dengan bukti adanya peningkatan skor sebesar 28 dari pra siklus sampai siklus kedua. Shidiq, Mulawarman, \& Awalya (2020) menunjukkan bahwa 16 siswa SMP IT Insan Cendekia Semarang yang memiliki ketegori tinggi efektif diintervensi dengan konseling behavioral melalui behavior contract dengan bukti adanya penurunan skor sebesar $29 \%$. Artinya hasil penelitian ini mendukung penelitian sebelumnya tentang teknik behavior contract dalam bingkai konseling kelompok behavioral efektif untuk mereduksi prokrastinasi akademik.

\section{SIMPULAN}

Skor pretest dan posttest prokrastinasi akademik siswa setelah dianalisis menggunakan Wilcoxon Signed Rank Test Statistics menunjukkan bahwa ditemui perbedaan hasil pretest dan posttest siswa sebelum dan sesudah diberikan treatment. Hal tersebut menunjukkan bahwa prokrastinasi akademik siswa dapat menurun setelah diberikan lima kali treatment. Artinya teknik behavior contract dalam bingkai konseling kelompok behavioral efektif mereduksi prokrastinasi akademik siswa. Berdasarkan temuan tersebut Peneliti selanjutnya disarankan untuk memakai Pretest-Posttest Control Group Design.

\section{DAFTAR RUJUKAN}

Asif (2011) Asif S.E. 2011. Clinical Implications of Academic Procrastination. Dissertation. Los Angeles: Doctor of Psychology at Alliant International University Los Angeles. ProQuest LLC

Burka, J. B \& Yuen, L. M. 2008. Procrastination : Why you Do It, What To Do About It. New York : Perseus Books Group

Corey. G. 2009. Theory and Practice of Counseling and Psychoterapy. USA: Brooks/Cole.

Deniz M. E, Traş Z, \& Aydoğan Didem. 2009. An Investigation of Academic Procrastination, Locus of Control, and Emotional Intelligence. Journal Educational Sciences: Theory \& Practice. 9 (2): 623632

Fauzan, L. 1992. Modul Ancangan Konseling Kelompok Behavioral. Malang: Departemen Pendidikan dan Kebudayaan.

Fauzan, L. 2004. Pendekatan-pendekatan Konseling Individual. Malang: Elang Mas. 
Efektor, Volume 8 Issue 2, 2021, Pages 176 - 183

Dwi Kresminia Ningsih', IM. Hambali2, Diniy Hidayatur Rahman ${ }^{3}$

Fauzan, L. 2009. Memberdayakan Behavior Contracts untuk Melesatkan Perkembangan Pribadi. Online: https://lutfifauzan.wordpress.com/2009/08/09/kontrak-perilaku/. Diakses pada 25 Agustus 2020.

Ferrari, Jr., Johnson,J.L., \& McCown.W.G. 1995. Procrastination and Task Avoidance.New York: Plenum Press.

Hambali, I. M., Putrisari, F., \& Handarini, D. M. 2017. Hubungan self efficacy, self esteem dan perilaku prokrastinasi siswa madrasah aliyah negeri di Malang Raya. TERAPUTIK: Jurnal Bimbingan dan Konseling, 1(1), 60-68. Dari https://core.ac.uk/download/pdf/143976603.pdf

Kartadinata \& Sia (2008) Kartadinata, I, \& Sia, T. 2008 Prokrastinasi Akademik dan Manajemen Waktu, ANIMA: Journal Indonesian Psychological. 23(2).

Knaus,Willam,Ed.D. (2010). End Procratinastion Now!. New York

Komalasari,Gantika. Eka Wahyuni. Karsih. 2011. Teori dan Teknik Konseling. Jakarta: Indeks.

Latipun.2017. Psikologi Konseling. Malang: Universitas Muhammadiyah Malang.

Mahardika, N. 2020. Mereduksi Disfungsional Prokrastinasi Akademik Melalui Layanan Konseling Kelompok Dengan Teknik Behavior Contract. Biblio Couns: Jurnal Kajian Konseling dan Pendidikan, 3(1), 15-22. Dari http://journal.umsu.ac.id/index.php/biblio/article/view/4672

Munawaroh, M. L., Alhadi, S., \& Saputra, W. N. E. 2017. Tingkat prokrastinasi akademik siswa sekolah menengah pertama muhammadiyah 9 Yogyakarta. Jurnal Kajian Bimbingan dan Konseling, 2(1), 26-31. Dari http://journal2.um.ac.id/index.php/jkbk/article/view/314.

Nitami, M., Daharnis, D., \& Yusri, Y. 2015. Hubungan motivasi belajar dengan prokrastinasi akademik siswa. Jurnal Konselor Universitas Negeri Padang, 4(1), 1-12. Dari http://ejournal.unp.ac.id/index.php/konselor

Purnama, A. S., Mursidi, A., \& Trisnawati, K. A. 2019. Behavioral Counseling Effectiveness Behavior Contract Technique to Decrease Behavior Academic Procrastination of Students. International Journal for Educational and Vocational Studies, 1(7), 760-764. Dari https://ojs.unimal.ac.id

Rahman, D. H. 2019. Model hubungan faktor-faktor yang mempengaruhi prokrastinasi penyelesaian skripsi dalam perspektif Rational Emotive Behavior Therapy. Disertasi tidak diterbitkan. Malang: Program Pascasarjana UM.

Rokhman, M. K., Sucipto, S., \& Masturi, M. 2020. Mengatasi Prokrastinasi Akademik Melalui Konseling Behavioral dengan Teknik Behavior Contract. Jurnal Prakarsa Paedagogia, 2(1). Dari https://jurnal.umk.ac.id/index.php/JKP/article/view/4310

Romlah, T. 2018. Teori dan Praktek Bimbingan Kelompok. Malang: Universitas Negeri Malang.

Sidiq, M. S., Mulawarman, M., \& Awalya, A. 2020. The Effectiveness of Behavioral Counseling With Token Economy and Behavior Contract Techniques to Reduce Academic Procrastination. Jurnal Bimbingan Konseling, 9(2), 76-84. Dari https://journal.unnes.ac.id/sju/index.php/jubk/article/view/36975

Sugiyono, 2010. Metode Penelitian Kuantitatif Kualitatif dan R\&D. Bandung: Alfa Beta

Widyastari, D., Atrizka, D., Ramadhani, B., \& Damanik, D. S. 2020. Prokrastinasi Akademik Ditinjau Dari Kontrol Diri Pada Siswa-Siswi SMA Swasta Ar-Rahman Medan. Jurnal Penelitian Pendidikan, Psikologi dan Kesehatan (J-P3K), 1(2), 82-91.

Widiyastuti, T.,Muhammad J., Sugiyadi. 2016. Konseling Kelompok dengan Teknik Behavior Contract terhadap Penurunan Prokrastinasi Akademik Siswa. Jurnal Program Studi Bimbingan Konseling Fakultas Keguruan dan IImu Pendidikan Universitas Muhammadiyah Magelang. Dari http://journal.ummgl.ac.id/index.php/edukasi/article/view/487 